\title{
A Multicultural Library: Strategies for the Twenty-First Century
}

\section{Veronica E. Nance-Mitchell}

\begin{abstract}
Demographic trends indicate that the economy will be dependent on the contributions of minorities and women because they will comprise 50 percent of the workforce. Library schools and institutions of higher education must be prepared to meet this demand of an increasingly multicultural population. However, minorities are still underrepresented in librarianship. Therefore, colleges and universities must be committed to affirmative action initiatives and the recruitment and retention of minority library students, and to mentoring, networking, and providing job opportunities.
\end{abstract}

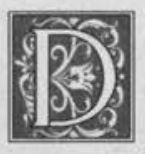

espite Title VII of the Civil Rights Act of 1966, which banned discrimination based on race, color, religion, sex, or national origin, minority groups remain underrepresented in education and employment. As society moves toward an increasingly multicultural population, educators, employers, and employees need to develop a multicultural perspective. This perspective should reflect the rapidly changing American demographics.

Research indicates that over the next twenty years, the population is expected to grow by forty-two million. Hispanics will account for 47 percent of this growth; African Americans, 22 percent; Asians and other people of color, 18 percent; and whites, only 13 percent. ${ }^{1}$ Current librarian demographics do not represent this rapidly changing population. All libraries (academic, public, and special) have a role to play in creating an environment conducive to a multicultural population. Therefore, this article attempts to identify strategies for creating a multicultural library based on the following significant areas: (1) implications of affirmative action; (2) recruitment and retention of minority students in library education; and (3) hiring minority librarians and networking.

\section{Implications of Affirmative Action}

In order to address the current and future effects of affirmative action, its historic purpose must be examined. The Civil Rights Act of 1957, the first major legislation of its kind since Reconstruction, created the United States Commission on Civil Rights, an assertive unit in the government's struggle against discrimination. However, it was the Civil Rights Act of 1964 that mandated the end of discriminatory practices based on race, ethnicity, and gender. Title VI prohibited discrimination based on color or national origin in any program receiving federal funds. Title VII prohibited employment discrimination in institutions with fifteen

Veronica E. Nance-Mitchell is a Reference Librarian at the University of the District of Columbia, Washington, D.C. 
or more employees. Legislators created the Equal Employment Opportunity Commission to enforce the 1964 act. Executive Order 11246, signed by President Lyndon Johnson in 1965, prohibited discrimination in any agency receiving federal contracts of more than $\$ 10,000$ in institutions with more than fifty employees. Programs that received federal contracts of more than $\$ 50,000$ were required to write an affirmative action plan that demonstrated the inclusion of women and minorities. ${ }^{2}$

Although Executive Order 11246 was a major step in affirmative action initiatives, it was Executive Order 10925 under President John, Kennedy that attempted enforcement. Executive Order 10925 required the filing of regular compliance reports so that the hiring and employment practices of federal contractors could be monitored. It authorized publication of the names of noncomplying contractors and termination of the rights of such contractors to do business with the federal government. However, no federal contractors were ever prevented from doing business with the federal government for not meeting hiring goals. ${ }^{3}$ No steps were taken on any basis until President Jimmy Carter's administration, and those occurred because of extreme noncompliance and noncooperation with laws and regulations governing federal contracts-never for just failure to meet hiring goals. Today, it is more important than ever that affirmative action initiatives be enforced. Historically, equal employment opportunities were imposed by government order rather than being selfinitiated. Thus, government-imposed programs are viewed as wasteful and unnecessary. But government-imposed affirmative action will always be necessary until society becomes color blind. As demographics change, the composition of the labor force also will change. As all minorities enter the workforce, more labor power will be generated to meet the needs of the economy. The attitude that affirmative action is unnecessary reinforces the historical view that diverse people are not qualified and that affirmative action was a poor compromise. In part, this attitude was the result of a lack of understanding about the meaning of affirmative action. ${ }^{4}$

There will be no prosperity if the nation's workplaces and educational institutions do not respond aggressively to demographic trends. However, before that can take place institutions must adopt a multicultural perspective. A true multicultural perspective can be defined as the achievement of a new level of knowledge and emotional awareness that enables people from various cultures to accept new experiences more readily. These people then develop and support programs that help people move from one stage of multicultural development to the next. ${ }^{5}$

Astep toward multiculturalism would involve overcoming stereotypes and myths. The biggest myth is that affirmative action constitutes reverse discrimination. Actually, "the purpose of the establishment of equal opportunity nondiscrimination laws was to eliminate discrimination suffered by people of color and religious practices not considered mainstream. No legislator ever claimed that a law was needed to protect Protestants from racial or religious discrimination. Laws were actually enacted by Congress to provide protection for all. High standards of proof of discrimination are always required by the courts. White victims of discrimination could expect equitable relief as could African American victims." ${ }^{1}$ Because few reverse discrimination cases have been lodged, little evidence of reverse discrimination exists. Although equal opportunity has increased the presence of diverse people in nontraditional jobs, usually it has not substantially strengthened their individual powers or their collective voice. Although they are present in more technical jobs and at higher management and profes- 
sional levels, they remain marginal in many respects. Why? Because most organizations and managers continue to operate under the assumption that anyone not considered a member of a majority group is a liability rather than an important asset. This attitude causes lower productivity, increased turnover, and more discrimination complaints. To address these problems before they worsen, organizations must look critically at their internal cultures and determine what needs to change if diversity is to become a constructive rather than a destructive force?

\section{Recruitment and Retention of Minority Students in Library Education}

Library schools and institutions of higher education should incorporate multiculturalism as part of their annual longrange plans and goals. Institutional goals and plans should reflect these changing demographics. A recent report of shifting enrollments in elementary and secondary schools indicates a significant shift. According to the report from the Statistical Forecast of the U.S., Hispanic enrollment is expected to increase by 54 percent to an estimated 5.1 million in 1994, up from approximately 3.3 million in 1985 . Native Americans and Alaska natives enrolled in school are expected to increase by 29 percent, but they still remain the smallest group, with about 414,000 students in 1994 up from 321,000 in 1985 . African American students will remain the second largest racial or ethnic group in public schools behind whites, but this group is expected to increase by only 13 percent to approximately 67 million in 1994, up from about 5.9 million in 1985. By 1995, the report projects more than 29 percent of the public high school graduates in sixteen states and the District of Columbia will be nonwhite or Hispanic. ${ }^{8}$

Most higher education institutions have been rather slow in reflecting this enrollment trend. According to a 1990 report by the National Center for Education Statistics, African Americans consti- tute 12.3 percent of the population but only 87 percent of college enrollment and 5.7 percent of college graduates. Hispanics, who account for 7.7 percent of the population, make up 49 percent of higher education enrollments and 2.7 percent of graduates. Although Native Americans, Hispanics, and African Americans represented 14 percent of university enrollments in 1986, they received just 9 percent of degrees, 8 percent of master's degrees, and 6 percent of doctorates awarded. ${ }^{9}$

According to a 1991-92 report by the National Center for Education statistics, 4,893 master of library science degrees were conferred over that time period. Of those, 4,230 were conferred to whites and only 159 to African Americans, 106 to Hispanics, 148 to Asian, and 8 to Native Americans. ${ }^{10}$ These data indicate the continued decline of minority graduates from library schools. Some minorities consider librarianship a low-status profession. If so, why do so many white students choose to enter the profession? Most studies show several reasons for the underrepresentation of minority library students, including educational background, minority attitudes toward libraries, social status of the student, competition from other professions, lack of opportunity to work in a library, inadequate scholarship support, lack of minority faculty in library schools, and poor recruiting programs or no recruiting initiatives. To address these areas, especially in recruitment, the institutional climate and structure must change to reflect the changing demographics. Increasing the number of minority librarians starts at the higher education level. But, first, institutions must assess their culture and campus climate.

According to Gillett-Karam, "the concept of climate embraces the culture, habits, decisions, practices, and policies that make up campus life. It is the sum of the daily environment and central to the comfort of minority students, staff, faculty and administrators experience on cam- 
pus. Students and other members of the campus community who feel unwelcomed or alienated from the mainstream of campus life are unlikely to remain. If they remain they are unlikely to be successful."11

To promote diversity in the campus climate, administrators need to assess the situation, which should almost always begin with an institutional self-analysis and move to an environmental analysis. The assessment should revolve around diversity needs and the responses of each segment of the institution (administration, faculty, staff, and students). The pur-

\section{Therefore, minority students should be aware of these opportunities and the needed qualifications to enter graduate programs in the field.}

poses of such an assessment are to understand clearly the internal and external situation to discover why the current situation exists and to decide how to rectify the situation. The current situation should be assessed by examining the following items: the current percentage of minority administrators; recruitment efforts; retention of minority faculty and students; salary and professional opportunities; and the perceptions of the institutional climate. ${ }^{12}$

Institutions should consider several possible outcomes when creating a diversity program as they assess their program. According to Nina Buchanan and John Feldhusen, the predicted outcomes of a diversity program should follow four lessons learned from industry:

1. Know what you are trying to produce.

2. Monitor the processes that are used to produce the product.

3. Evaluate the product.

4. Make corrections if the product does not meet expectations. ${ }^{13}$

Institutions should focus on recruitment efforts after closely examining their internal climate. Since the mid-1970s, the number of students entering library education programs has slowly declined. ${ }^{14}$ Because of decline in enrollment, there may be an increase in the demand for librarians. Other factors may include technological advances that require training in utilizing the computer for various library functions (e.g., research, circulation). To meet this demand, institutions must recruit minorities in response to demographic changes, and as a first step in recruitment, start educating students about opportunities in librarianship before they reach the secondary level. Many students do not enter the library profession because they are unaware of its career opportunities. Librarians, educators, administrators, and student advisors can promote awareness of career options in librarianship. The information explosion and the increase in computer technology offer students many options in the library and information science profession. Therefore, minority students should be aware of these opportunities and the needed qualifications to enter graduate programs in the field. Some of the opportunities include: information managers; university or college librarians; information entrepreneurs; and research librarians for business, government, law, and medicine. Because of the interdisciplinary character of library and information studies, students with a strong undergraduate preparation in any discipline can pursue graduate work. ${ }^{15}$

Second, institutions must be committed to affirmative action and equal opportunity. Employment measures must do more than take a passive approach to the elimination of discrimination. All recruitment and advertisement materials state, "We do not discriminate on the basis of race, color, creed, or national origin." Colleges and universities appeared to be saying that the removal of blatant discriminatory policies and advertising languages would make everything all right. However, because of this passive ap- 
proach, little change has occurred in the institutional composition of students, faculty, and staff. ${ }^{16}$

Furthermore, advertising in publications has not been successful in recruiting minority staff members. New measures that have been effective at universities such as Texas A\&M include: (1) coordinating a board minority registry and the National Minority Faculty Identification Program Directory; (2) mailing vacancy announcements to ethnic and/or African American organizations; and (3) minority internship programs. ${ }^{17}$

Serbrenia Sims lists several reasons for emphasizing diversity in faculty and staff. First, diversified faculty and staff provide support for students from a particular underrepresented group on campus. Second, diversification of faculty and staff is important in establishing a commitment to minority students' futures and to helping these students recognize this commitment. Third, diversification of staff creates a more relaxed, homelike environment for students, faculty, and staff on campus. Fourth, diversification of faculty and staff is likely to contribute to curriculum development, content, and instructional techniques. ${ }^{18}$ Participation in college does not mean enrollment, it means graduation-and it means getting jobs. Colleges and universities must retain minority students and provide them with role models whose successes become a pattern for student achievement and student goals. Diversity is achieved by the commitment of leaders. Minority participation must be integral to the mission and workings of institutions of higher education. ${ }^{19}$

Once institutions have taken steps to recruit minority students, they must focus their efforts on retention. Retention can be achieved by developing support services. According to Gillett-Karam, "institutions can provide training to white faculty to help them become more understanding of minority student needs, and encourage faculty members to become aware of the new issues in their discipline that focus specifically on minority issues and concerns." ${ }^{20}$ It also is advisable to develop financial incentives for departments, such as minority fellowship funds or graduate assistantships and affirmative action grants.

Several universities have implemented internship programs to increase the number of minorities in the field of library and information science. There are programs at Iowa State University and the University of New Mexico, to name a few. However, programs at the University of California-Santa Barbara, and the University of Michigan should be models for all academic libraries to mirror. The goal of these programs is to promote training, library experience, and job placement for minorities. ${ }^{21}$ The objectives of these programs are to equip the interns with basic training in library functions and skills. At the University of California-Santa Barbara, interns receive oneyear contracts as assistant librarians with full benefits. ${ }^{22}$

In 1988, the president of the University of Michigan issued the Michigan Mandate. The order was for the university to become a multicultural community. This mandate came in the wake of much campus unrest and several serious racial incidents. Acting in that context, the library initiated its work with verbal support from the university. One outgrowth of this mandate was establishment of the University of Michigan's Library Diversity Committee. ${ }^{23}$ The purpose of the committee is to provide leadership to the staff by promoting understanding across racial and cultural lines as well as by addressing the issues of gender, age, religion, and the concerns of people with disablilities. ${ }^{23}$ The University of Michigan Library received the university's first affirmative action award and is recognized as a model diversity program on campus. This would not have been possible without the commitment of the library administration, librarians, and staff. ${ }^{24}$ 
The focus of an institutions's efforts to retain diverse students also should include outreach and academic support services. An effort has been made in the past several years to reach out to multicultural students and teach them the library skills they need to succeed at the university and beyond. The Learning Resources Library at the University of the District of Columbia developed a bibliographic instruction program to support an increasingly multicultural student population (the university has more than 5,000 international students). The library, in association with the English Department, provides bibliographic instruction (BI) each semester. The primary goals of the BI program are to: (1) inform students about the Learning Resources Divisions' collections and services; (2) teach students the library skills they need in the academic environment by acquainting them with the variety of resources available in modern libraries; and (3) teach use of library and media resources (Aladin online computer catalog, CD-ROM, printed indexes) for writing research papers. ${ }^{25}$ The BI program provides a communication link with the teaching faculty and promotes the university's mission in serving economically disadvantage students.

Another outreach service of the Learning Resources Division at the University of the District of Columbia is the Black Film Institute. It plays a significant part by introducing students to films by and about blacks from other cultures. Public film showings are sometimes accompanied by the live commentary of prominent personalities in the field. For example, the institute has offered a series of films that focused on aspects of black cinema. These films have included new works from the African continent, Hollywood's "Negro Problem" films of the 1950s, and the work of independent filmmaker Spencer Williams. The institute also hosted several screenings of the 8th Asian American Film Festival. As part of the festival, several guest speakers noted for their expertise in the genre participated in a panel discussion. These are examples of programs that can support a multicultural student population.

\section{Hiring Minority Librarians and Networking}

After minority librarians have completed the academic requirements to meet the necessary job qualifications, they should be recruited for the jobs. However, many libraries do not hire minority applicants because they assume applicants are not qualified and inexperienced. Increasing the number of minority librarians is a crucial aspect of changing institutional culture and climate. But "engaging in the damaging rhetoric that there are no qualified minorities for the position is damaging and accounts for additional exclusionary beliefs and policies." 26

Many exclusionary practices that contribute to the underrepresentation of minorities are rooted in the single-mistake syndrome. According to Gillett-Karam, this syndrome is based on the assumption that if a woman or member of a racial ethnic minority has made a mistake, that mistake is proof that the whole group is not competent. Statements along the lines of "we shouldn't have taken the risk" are aimed at racial-ethnic minorities and women and their positions of leadership. The question becomes, is it alright, is it permissible, for women or members of racial-ethnic minorities to make a mistake, to be risk takers, or to be change agents? Of course, they should be able to make mistakes and learn from them. However, this "I told you so, they can't do it" perception remains a part of social reality ${ }^{27}$ As one institutional leader stated, "If affirmative action is no longer purposeful, then it does not allow for the nurturing of the idea of opportunity. This idea can easily fall out of favor and be eliminated from the consciousness of employers." 28

Every institution should have an affirmative action search policy. This policy 
must indicate the specific means by which the institution will make efforts to identify minority and women candidates for jobs. Such means are expected to go beyond posting and advertising the availability of positions, and should include, but not be limited to, such efforts as: (1) personal telephone and/or written communication with colleagues or other groups who can assist in locating candidates; (2) visits by members of search committees to organizations or institutions; and (3) personal communication with minority and female colleagues at professional gatherings. ${ }^{29}$ An affirmative action search policy should also include the following: (1) a minority staff development and recruitment program that will utilize minority staff representation on search committees; (2) discretionary funds available for minority recruitment; and (3) carefully written job descriptions for accurate indication of employee requirements. Furthermore, institutions should target their recruitment efforts on areas most attractive to minorities. According to a 1986 Office for Library Personnel Resources survey by ethnicity, "minority students were attracted to the field because of the ' $h i-$ tech' $^{\prime}$ nature of the work. African Americans scored this characteristic the highest at 39.2 percent, compared to the overall population who scored it at 29.5 percent. African Americans also scored management opportunities as an attraction to the field at a higher rating ( 46.3 percent) than the overall population who scored it at 27.8 percent." ${ }^{30}$

Mentoring and networking also are important measures for inclusionary practices, and such measures are responsible for turning national attention to the underrepresentation of women and minorities in positions of leadership. Mentoring involves the care and concern of a visionary or a decision maker who breaks away from the mold of self-preservation and seeks to help others demonstrate their unique competencies.$^{31}$ Researchers have listed several benefits that might accrue from mentorships with diverse students:

- It allows students to work in a noncontrolled setting, requiring them to interact with others who are fundamentally different from themselves. This difference might include age, race, sex, cultural, or socioeconomic orientation.

- Students acquire marketable skills necessary to qualify for a job.

- Students are forced to test and develop career goals by experiencing working conditions in their field and by discussion with mentors and at school. ${ }^{32}$

One organization that provides mentoring and networking opportunities is the President's Roundtable, a nationwide network of African American expertise and an affiliate of the National Council on African American Affairs. Its mission is to provide African American community college presidents with an operational network to identify and respond to issues affecting African Americans in community colleges. The network also provides mentoring opportunities for African Americans; the sharing of profes-

\section{Mentoring and networking also are important measures for inclusionary practices, ....}

sional resources; national and international professional opportunities for African American chief executive officers (CEOs); and support for the goals and objectives of the National Council on African American Affairs. In pursuit of its mission, President's Roundtable also provides many services. Some of the services include: (1) mentoring opportunities for African Americans within member institutions; (2) monitors to review inequity in the delivery of educational and other services provided to African Americans in community college education; (3) a continually updated list of African American CEOs with information about each president's availability as a resource; and 
(4) a third-nation support package that emphasizes current and emerging technology for appropriate nations as requested. $^{33}$

Mentoring is important to the inclusionary process of minority employees. Too often, new minority employees feel isolated and not fully accepted in the organization's mainstream. The purpose of mentoring is to: (1) streamline the assimilation process of new employees; (2) promote the professional development of their proteges and contribute to an effective and productive library operation; and (3) promote the exchange of viewpoints and ideas by sharing knowledge and experience. These goals contribute to a staff with improved morale, lower turnover, greater efficiency, and a better understanding of one another's responsibilities. ${ }^{34}$

\section{Conclusion}

To achieve a multicultural library, institutions must be committed to creating an environment conducive to a diverse population. Creating such an environment requires a commitment to recruitment in education and employment, mentoring, and networking. Faculty and administration of library schools should be motivated to provide strategies to eliminate the gap between access and the completion rate of minorities in library education. The strategies can include the establishment of diversity committees that will have three primary roles: (1) to advise the administration; (2) to educate and serve as an organizational model for other staff members; and (3) to participate in and organize diversity programs. Furthermore, the strategies should include programs that provide academic support, financial aid, and job opportunities. All of these strategies require a commitment to affirmative action initiatives. Institutions have the responsibility and the obligation to establish diversity. They must realize that education for all diverse populations is a catalyst for change within the community. People need to work on core values, and there are no shortcuts. Affirmative action requirements cannot be met without comment and commitment. As an anonymous librarian said, "Librarianship is about sharing and increasing one's knowledge. Those who are not willing to share should not be in the profession."

\section{Notes}

1. Marilyn Loden, Workforce America: Managing Employee Diversity As a Vital Resource (Homewood, Ill.: Business One Irwin, 1991).

2. Rosemary Gillett-Karam et al., Underrepresentation and the Question of Diversity: Women and Minorities in the Community College (Washington, D.C.: Community College Pr., 1991).

3. Ibid., 16.

4. Loden, Workforce America, 30.

5. Serbrenia J. Sims, Diversifying Black Colleges and Universities: A New Higher Education Paradigm (Westport, Conn.: Greenwood Pr., 1994).

6. Loden, Workforce America, 33.

7. Ibid., 27.

8. James E. Pearson, Statistical Forecast of the United States (Detroit: Gale Research, 1993).

9. Manuel J. Justiz et al, Minorities in Higher Education (Phoenix: Oryx Pr., 1994).

10. U.S. Department of Education (Washington, D.C.: National Center for Education Statistics, 1994). The statistics were compiled from an Integrated Post-secondary Education Data System "Completions" survey.

11. Gillett-Karam et al, Underrepresentation and the Question of Diversity, 217.

12. Sims, Diversifying Black Colleges, 165.

13. Ibid., 59.

14. Benjamin F. Speller, Educating Black Librarians (Jefferson, N.C.: McFarland, 1991).

15. "Minority Recruitment and Retention," Spec Kit 167 (Washington, D.C.: Office of Management Services, ARL, 1990). 
16. Sims, Diversifying Black Colleges, 122.

17. "Minority Recruitment and Retention," 20.

18. Sims, Diversifying Black Colleges, 72.

19. Gillett-Karam et al, Underrepresentation and the Question of Diversity, 210.

20. Ibid., 236.

21. Joseph A. Boissé and Connie V. Dowell, "Increasing Minority Librarians in Academic Research Libraries," Library Journal 12 (Apr. 15, 1987): 52-54.

22. Ibid., 53.

23. Donald E. Riggs and Patricia A. Tarin, Cultural Diversity in Libraries (New York: NealSchuman, 1994).

24. Ibid., 95-98.

25. Taken from the "Annual Report of the University of the District of Columbia Learning Resources Division."

26. Justiz et al, Minorities in Higher Education, 14.

27. Gillett-Karam et al, Underrepresentation and the Question of Diversity, 154.

28. Ibid., 12.

29. "Minority Recruitment and Retention," 363.

30. Speller, Educating Black Librarians, 109.

31. Gillett-Karam et al, Underrepresentation and the Question of Diversity, 154.

32. Sims, Diversifying Black Colleges, 75.

33. Gillett-Karam et al, Underrepresentation and the Question of Diversity, 154-57.

34. "Minority Recruitment and Retention," 72.

\section{Letter}

To the Editor:

Thank you very much for publishing my article, "Publishing in the Journal Literature of Library and Information Science" in the July 1996 issue of CERL.

I am writing to apologize for a couple of errors that I did not catch in the page proofs. They are in Table 1. Fortunately, the errors do not affect the text, discussion, or conclusions in any way. However, I would like to set the record straight.

My sincere apologies for letting these errors slip into the final manuscript. I intend to e-mail the editors of the journals where the errors were made to let them know that I recognize the errors. Thank you.
The correct numbers are as follows:

\begin{tabular}{|lccc|}
\hline \multicolumn{4}{|c|}{ Table 1 } \\
\hline $\begin{array}{l}\text { Journal } \\
\text { Title }\end{array}$ & $\begin{array}{l}\text { \% of fea- } \\
\text { ture art. }\end{array}$ & $\begin{array}{c}\text { \# of } \\
\text { unsolic. }\end{array}$ & $\begin{array}{c}\text { \% of } \\
\text { unsolic }\end{array}$ \\
\hline $\begin{array}{l}\text { Library } \\
\text { Mosaics }\end{array}$ & 25 & 20 & 90 \\
RBML & & & \\
$\begin{array}{l}\text { School Libr. } \\
\text { Media Qrtrly. }\end{array}$ & & $25-50$ \\
\hline
\end{tabular}

Barbara Via

University at Albany, SUNY bv848@cnsvax.albany.edu 